\title{
Effect of injection strategies on a single-fuel RCCI combustion fueled with isobutanol/isobutanol+DTBP blends
}

\author{
Amir Mohammadian ${ }^{\mathrm{a}}$, Hamed Chehrmonavari ${ }^{\mathrm{a}}$, Amirhasan Kakaee ${ }^{\mathrm{a}, *}$, Amin \\ Paykani $^{\text {b }}$ \\ ${ }^{a}$ School of Automotive Engineering, Iran University of Science and Technology, Narmak, Tehran, \\ Iran \\ ${ }^{b}$ School of Engineering and Computer Science, University of Hertfordshire, Hatfield, UK
}

\begin{abstract}
In recent years, improved combustion controllability in terms of in-cylinder reactivity stratification by using two different fuels led to introduction of dual-fuel reactivity controlled compression ignition (RCCI) strategy. This strategy has the potential to operate with a single low reactivity fuel and direct injection (DI) of the same fuel blended with a small amount of cetane improver. In the present study, a numerical investigation was conducted to simulate a single-fuel RCCI engine fueled with isobutanol - isobutanol+20\% di-tert-butyl peroxide (DTBP) with an optimal injection strategy. Firstly, the effects of start of injection (SOI) timing, injection pressure, spray cone angle, and DI fuel ratio are explored. Secondly, the effect of DI fuel ratio reduction is discussed in each best case in order to decrease the high DI requirement. The results showed that $-88^{\circ}$ ATDC SOI, 1400 bar injection pressure, and $45^{\circ}$ spray cone angle case can improve the performance and emissions compared to the baseline case (SOI=-58 ATDC, spray angle $=72.5^{\circ}$, injection pressure $=600 \mathrm{bar}$ ). Moreover, it was found that by advancing the SOI timing to $-88^{\circ}$ ATDC, a $20 \%$ reduction in DI ratio, $3.3 \%$ increase in gross indicated efficiency (GIE) together with reductions in $\mathrm{CO}$, and $\mathrm{NO}_{x}$ emissions by 3.56 and $0.254 \mathrm{~g} / \mathrm{kW}-\mathrm{hr}$, could be achieved, respectively.
\end{abstract}

\footnotetext{
* Corresponding author

Email address: kakaee_ah@iust.ac.ir (Amirhasan Kakaee)
} 
Keywords: RCCI combustion, injection strategy, isobutanol, emissions, efficiency

\section{Introduction}

The concerns on energy security, greenhouse gas emissions (GHGs), and combustion generated pollutant emissions have a considerable impact on the future development of internal combustion (IC) engines. In order to reduce both environmental and economic costs of IC engines, combustion research has been led to investigations of advanced combustion strategies based on low temperature combustion (LTC) [1], which have the potential to achieve simultaneously low emissions of both nitrogen oxide $\left(\mathrm{NO}_{x}\right)$ and soot while maintaining high thermal efficiency [2, 3]. The LTC strategy includes homogeneous charge compression ignition (HCCI), partially premixed compression ignition (PPC), and reactivity controlled compression ignition (RCCI) [4].

In order to overcome the disadvantages of HCCI and PPC strategies in terms of direct combustion rate control, RCCI combustion has been introduced [5]. In RCCI combustion, a low reactivity fuel (i.e., gasoline) was premixed through port injection and a high reactivity fuel (i.e., diesel) is directly injected into the combustion chamber; thus, more effective control over ignition timing and combustion rate can be achieved by adjusting the ratio of two fuels and the start of injection (SOI) of the direct-injected fuel [6].

In view of the attraction of RCCI combustion in terms of reactivity controlled, many researchers have devoted their attention to investigation of alternative fuels [7]. Despite of conventional low and high reactive fuels (i.e., gasoline and diesel, respectively), various types of fuels can be used with dual-fuel RCCI [8]. Some researches has contributed their own focus on the low reactivity fuels have included gaseous fuels namely natural gas [9-11], syngas [12], alcoholic fuels like ethanol [13--15], methanol [13, 16, 17] and butanol [18, 19], and the others focused on the high reactivity fuels such as biodiesel [20-22].

In order to enable RCCI strategy for commercial applications, efforts have 
been made to investigate single-fuel RCCI by utilizing a single fuel tank with a low reactivity fuel, together with a small secondary tank for a cetane improver. In these studies, a low reactive fuel was used as a port fuel injection (PFI), as well as DI fuel when doped with a small amount of cetane improver [13]. Another way towards commercialization is to achieve single-fuel RCCI using a mixture of reformer gas and high reactive fuel [23, 24]. Some recent studies regarding single-fuel RCCI strategy found in the literature are presented in Table 1 .

Table 1: Previous studies on single-fuel RCCI strategy

\begin{tabular}{cc} 
The LRF is fixed & The HRF is fixed \\
HRF: LRF + cetane improver (DTBP/2EHN & LRF: HRF + reformer gases \\
\hline
\end{tabular}

- Gasoline + DTPB - HD engine (Split-

ter 2010) [25]

- Gasoline + 2-EHN - HD engine (Han-

son 2011) 26]

- E10 (i.e. $10 \%$ ethanol+90\% gasoline) + - Syngas + Diesel - HD engine

2-EHN - LD engine (Kaddatz 2012) [27] (Chuahy 2017) [24]

- Gasoline/Ethanol/Methanol + DTBP/2 - Syngas + Diesel - HD engine

- EHN - LD engine - (Dempsey (Xu 2018) [28]

2013) [13]

- Gasoline + 2-EHN - Multi-cylinder

LD engine (Dempsey 2015) 29]

- Isobutanol + DTBP - HD engine

(Wang 2015 \& Delvescovo 2015) [18, 19]

DTBP and 2-ethylhexyl nitrate (2-EHN) are two of the most widely used cetane improvers in IC engine research. Splitter et al. [25] performed the experiments on a heavy-duty RCCI engine using a small percentage of $3.5 \%, 1.75 \%$, and $0.75 \%$ volume fraction of DTBP as a cetane improver with port injection 
gasoline stream at 6 and 9 bar IMEP, owing to make a comparison between of single (gasoline/gasoline $+\mathrm{DTBP}$ ) and dual (gasoline/diesel) fueling strategies of RCCI. Results of these experiments revealed that the performance and the emissions level were somewhat similar to dual-fuel case, means that a small amount of DTBP ( $0.2 \%$ of the total fueling) is able to increase the reactivity, but the low temperature heat release (LTHR) of single fueling dropped and advanced. The dropped LTHR caused a reduction in the compression work, therefore yielded an increased gross thermal efficiency (GIE) by $1 \%$.

Hanson et al. [26] carried out a study on gasoline-gasoline+3.5\% 2-EHN as a single-fuel case and then compared with gasoline-diesel as a dual fuel in a heavyduty RCCI engine at low load. Their findings were in agreement with the Splitter et al. [25] one's, and it was also perceived the single-fuel strategy is faster than dual-fuel strategy in terms of the high temperature heat release (HTHR) event.

To characterize the effects of 2-EHN and DTPB, Dempsey et al. [13] studied single-fuel RCCI combustion in a light-duty engine using gasoline, methanol and ethanol. The study showed that alcoholic fuels require higher amounts of cetane improver than conventional gasoline to be considered as a proper high reactive fuel. It was also shown that methanol has better response than ethanol to the cetane improver. Moreover, 2-EHN compared to DTBP was more capable of achieving a doped version with conventional gasoline while increasing $\mathrm{NO}_{x}$ due to its chemical structure.

Recently, Ansari et al. [30] conducted an experimental study of diesel-natural gas RCCI to explore the impact of high reactive fuel on combustion performance and emissions using two diesel fuel with different cetane numbers. They found that cetane number has the prominent role in RCCI performance by increasing the reactivity gradient within combustion chamber. Utilizing a high cetane number diesel as a replacement for a traditional diesel fuel resulted in a $2 \%$ enhancement in brake thermal efficiency and a reduction of 3 and $14 \mathrm{~g} / \mathrm{kWh}$ in $\mathrm{CO}$ and $\mathrm{HC}$ emissions, respectively.

Iso-butanol is an oxygenate bio-drive fuel with high oxygen content resulting in negligible soot emissions, which makes it an ideal candidate for RCCI com- 
bustion [31]. Wang et al. [18] and Delvescovo et al. [19] investigated the use of isobutanol as low reactive fuel and a mixture of that doped by $20 \%$ volume fraction of DTBP as high reactive fuel in a HD RCCI engine 2.44 L by means of experimental and numerical studies. Both studies indicated that single-fuel RCCI is achievable by isobutanol accompanied with DTBP as CN improver, but this fueling needs a higher amount DI compared with gasoline-diesel and isobutanoldiesel fueling; this is due to higher octane number of isobutanol. Also, increasing DI amount increased $\mathrm{NO}_{x}$ and $\mathrm{CO}$ emissions, which can be mitigated through optimizing injection strategy.

Although isobutanol as the low reactivity fuel of RCCI combustion mode has been studied by some researchers, its use in a single-fuel mode together with a cetane improver has not been addressed before. In the present work, a CFD study, was conducted using CONVERGE CFD software, and was validated against available experimental results. The aim of the current study is to determine an optimal injection strategy to minimize the high DI fuel amount in an RCCI engine fueled with isobutanol/isobutanol+20\%DTBP. The effects of injection parameters such as injection pressure, spray cone angle, and start of injection are invetigated. The information presented in this paper has relevance to future single-fuel RCCI concepts more suitable for vehicular applications.

\section{Numerical methodology}

\subsection{Case study}

The experimental data of a RCCI engine fueled with isobutanol - isobutanol + DTBP was acquired from Delvesevoco et al. [19] as a basis for numerical investigation. A caterpillar 3401E Single Cylinder Oil Test Engine (SCOTE) with a 6 -hole injector was used. The specifications of engine and injector, and operation conditions are presented in Table 2 and Table 3 , respectively. Physical properties of iso-butanol and DTBP, which would be needed to use in spray sub-models, are presented in Table 4 . 
Table 2: Engine and injector specifications [19]

\begin{tabular}{lc}
\hline Engine & \\
\hline Displacement (L) & 2.44 \\
Bore $\times$ Stroke (mm) & $137.2 \times 165.1$ \\
Connecting Rod Length (mm) & 211.6 \\
Compression Ratio & $14.88: 1$ \\
Piston Bowl Shape & Bathtub \\
Swirl ratio & 0.7 \\
Intake Valve Closing (IVC) & $-143^{\circ}$ ATDC \\
Exhaust Valve Opening (EVO) & $130^{\circ}$ ATDC \\
\hline Injector & \\
\hline Number of holes & 6 \\
Nozzle diameter (mm) & 250 \\
Included Spray angle & $145^{\circ}$ \\
\hline
\end{tabular}

\subsection{Computational model}

In the current study, CONVERGE CFD tool [32] is employed to perform the computational modelling of the RCCI combustion. The PFI iso-butanol with air is assumed to be a well-mixed charge at intake valve close (IVC), and the isobutanol with a small percent of cetane improver DTBP is injected directly. In CONVERGE, the spray process modeling, which is based on the LagrangianDrop and Eulerian-Fluid (LDEF) framework, is split into the physical sub-models including break-up, droplet collision, wall interaction, and vaporization. Another physical sub-model is considered to capture of turbulence flow. The physical submodels were used in this study, is presented in Table 5

In order to model the combustion process, the SAGE detailed kinetic solver [41] was applied to perform chemistry reaction calculations, integrated with a multi-zone model [42] for reducing run-time of simulations at each case. The detailed chemical mechanism proposed by Wang et al. [43], which includes 108 
Table 3: Operating condition [19]

\begin{tabular}{lc}
\hline IMEP (bar) & 6.5 \\
Engine Speed (RPM) & 1300 \\
Intake pressure (bar) & 1.38 \\
Intake temperature $\left({ }^{\circ} \mathrm{C}\right)$ & 40 \\
EGR ratio (\%) & 0 \\
Total fuel (mg) & 97 \\
Premixed fuel mass fraction (\%) & 40.6 \\
First/second DI mass fraction (\%) & $67 / 33$ \\
DTBP mass fraction (\% total DI mixture) & 20 \\
First SOI ( $\left.{ }^{\circ} \mathrm{ATDC}\right)$ & -58 \\
Second SOI $\left({ }^{\circ} \mathrm{ATDC}\right)$ & -37 \\
Injection pressure (bar) & 600 \\
\hline \multicolumn{1}{c}{ Table 4: Properties of iso-butanol and DTBP [18] } \\
\hline
\end{tabular}

species and 435 reactions, was used to represent DTPB and iso-butanol chemistry pathways. $\mathrm{NO}_{x}$ emissions were predicted through a mechanism in which 4 species and 12 reactions are included. Also, soot emission was determined by a two-step phenomenological Hiroyasu soot model [44]. 
Table 5: Physical sub-models

\begin{tabular}{lc}
\hline Sub-models & Models \\
\hline Spray break-up & Hybrid KH-RT [33, 34] \\
Droplet collision & No time counter (NTC) [35] \\
Drop drag & Taylor Analogy breakup (TAB) [36] \\
Wall film formation & O'Roruke model [37] \\
Vaporization & Frossling Correlation [38] \\
Turbulence & Modified RNG k-epsilon [39] \\
Wall heat transfer & Han and Reitz model [40] \\
\hline
\end{tabular}

\subsection{Model Validation}

Due to 6-hole injector, a 60-degree sector was taken into consideration for improvement of run-time calculations, as depicted in Figure 1. The base grid size was set to $1.4 \mathrm{~mm}$ in all three directions and an adaptive mesh refinement (AMR) with a scale of 2 for both temperature and velocity was used to capture the unpredictable changes due to the possibility of high gradients in some in-cylinder regions. In addition, a fixed embedding with a scale of 3 was employed to provide an extra resolution grid at near nozzle region for reducing mesh-dependencies of spray modeling process. Based on a work by Senecal et al. [45], a minimum cell size of $0.25 \mathrm{~mm}$, which was obtained in this study, can offer an adequate resolution for RANS-based spray simulations. All the simulations were performed from IVC to EVO.

Figure 2 shows the comparison between the average in-cylinder pressure and the corresponding heat release rate (HRR) predicted with current numerical model and experimental data. As depicted, the simulation of computational model is capable of capturing the start of combustion (SOC) and fairly accurately following the experimental pressure trace, though there are still differences that could be related to the uncertainty in the IVC temperature and the assumption of mixture homogeneity. For further validation of the computational model, 
the results of predicted and experimentally investigated engine performance and emissions, and also absolute error produced from the difference between those values are given in Table 6. As shown, the parameters related to performance are predicted reasonably well, but due to the use of a reduced kinetic mechanism, the emissions are under predicted. Accordingly, the simulated performance and emissions are within $3 \%$ and $8 \%$ error of the experimental, respectively. Overall, computational model can predict the features of an isobutanol - isobutanol + DTBP RCCI combustion.

Table 6: Performance and engine-out emissions comparison between experimental data [19] and current numerical model, with resulting absolute errors.

\begin{tabular}{lcccccccc}
\hline & \multicolumn{3}{c}{ Performance } & \multicolumn{5}{c}{ Emissions } \\
\hline & $\begin{array}{c}\text { IMEP } \\
(\mathrm{bar})\end{array}$ & $\begin{array}{c}\text { Combustion } \\
\text { eff. (\%) }\end{array}$ & $\begin{array}{c}\text { GIE } \\
(\%)\end{array}$ & $\begin{array}{c}\text { PPRR } \\
(\mathrm{bar} / \mathrm{deg})\end{array}$ & $\begin{array}{c}\mathrm{NO}_{x} \\
(\mathrm{~g} / \mathrm{kW}-\mathrm{h})\end{array}$ & $\begin{array}{c}\mathrm{HC} \\
(\mathrm{g} / \mathrm{kW}-\mathrm{h})\end{array}$ & $\begin{array}{c}\text { CO } \\
(\mathrm{g} / \mathrm{kW}-\mathrm{h})\end{array}$ & $\begin{array}{c}\text { Soot } \\
(\mathrm{g} / \mathrm{kW}-\mathrm{h})\end{array}$ \\
\hline Exp. & 6.5 & 94.9 & 47.8 & 7.1 & 0.3 & 3.8 & 26.9 & - \\
Sim. & 6.3 & 92.83 & 47.9 & 7.8 & 0.27 & 1.96 & 19.1 & 0.0354 \\
Absolute Error & 0.2 & 2.07 & 0.1 & 0.7 & 0.03 & 1.84 & 7.8 & - \\
\hline
\end{tabular}

\section{Result and Discussion}

Obtaining the optimal injection strategy that results in the reduction of DI fuel amount while maintaining high thermal efficiency and low emissions, re-

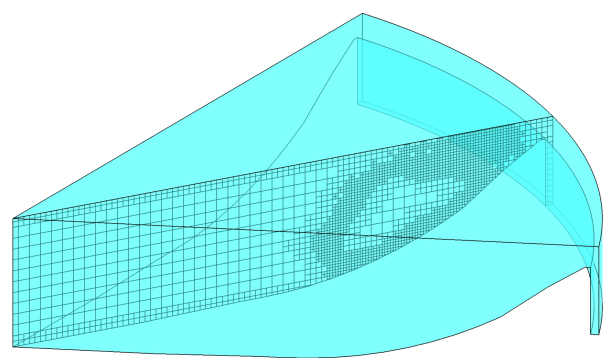

Figure 1: Computational geometry for the bathtub piston shown at $+3^{\circ}$ ATDC. 


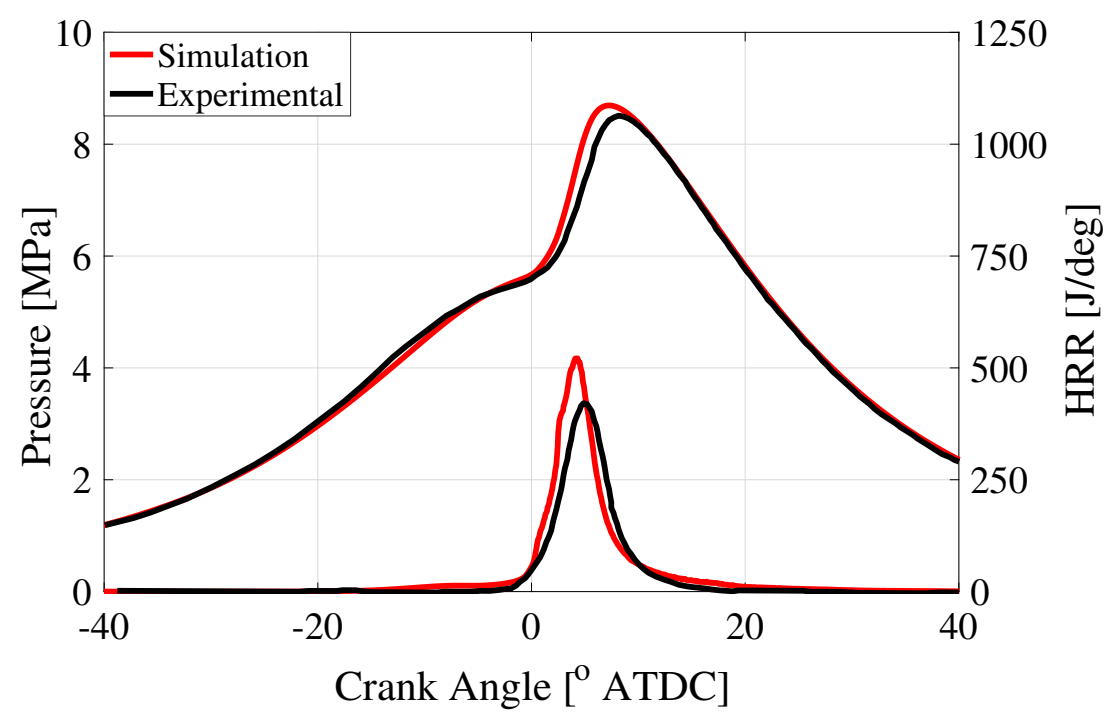

Figure 2: Comparison of experimental and predicted in-cylinder pressure and HRR.

quires a detailed analysis of the effect of each injection parameter. For this purpose, the effects of SOI timing, injection pressure, spray angle and DI ratio are discussed in the following sections. It should be noted that according to work by Higgen et al. [46], addition of cetane improvers has a negligible effect on the physical spray and combustion processes, and the primary effect of those is to diminish the chemical auto-ignition delay time due to increased reactivity of fuel; thus, this can help to isolate the optimal strategy injection from the effect of DTBP. Therefore, in this research, the amount of cetane improver is kept constant in all simulations.

\subsection{Effect of SOI}

In this section, the effects of injection timing on performance and emission are explored by sweeping start of injection (SOI) from $-88^{\circ}$ to $-28^{\circ}$ ATDC with a step of 10 crank angle degree (CAD), as all simulations used a fixed injection dwell of $21^{\circ}$ between the first and second injection timing. It should also be noted 
that the provided results consist of a constant global equivalence ratio of 0.33 and a fixed DI fuel ratio.

The variation of in-cylinder pressure and the corresponding HRR for the sweep of SOI is shown in Figure 3 . As seen, the start of combustion (SOC) is advanced and the combustion duration is decreased by sweeping SOI from the baseline to $-88^{\circ}$ ATDC. Also, increasing the level of premixing leads to maximum peak pressure at SOI timing of $-88^{\circ}$ ATDC.

On the other hand, retarding SOI from the baseline to $-38^{\circ}$ ATDC also results in an advanced SOC, but the combustion duration and the peak pressure do not change significantly. At SOI timing of $-28^{\circ}$ ATDC, the second injection event, which affects the SOC, is proceeding to introduce the mixing-controlled combustion because the mixing time is decreased for the mixture of isobutanol, air, and isobutanol doped with DTBP. Besides, it can be seen from the HRR result that initial rapid combustion occurs to shape HRR like an uncontrolled combustion phasing (i.e., premixed phase) of conventional diesel.

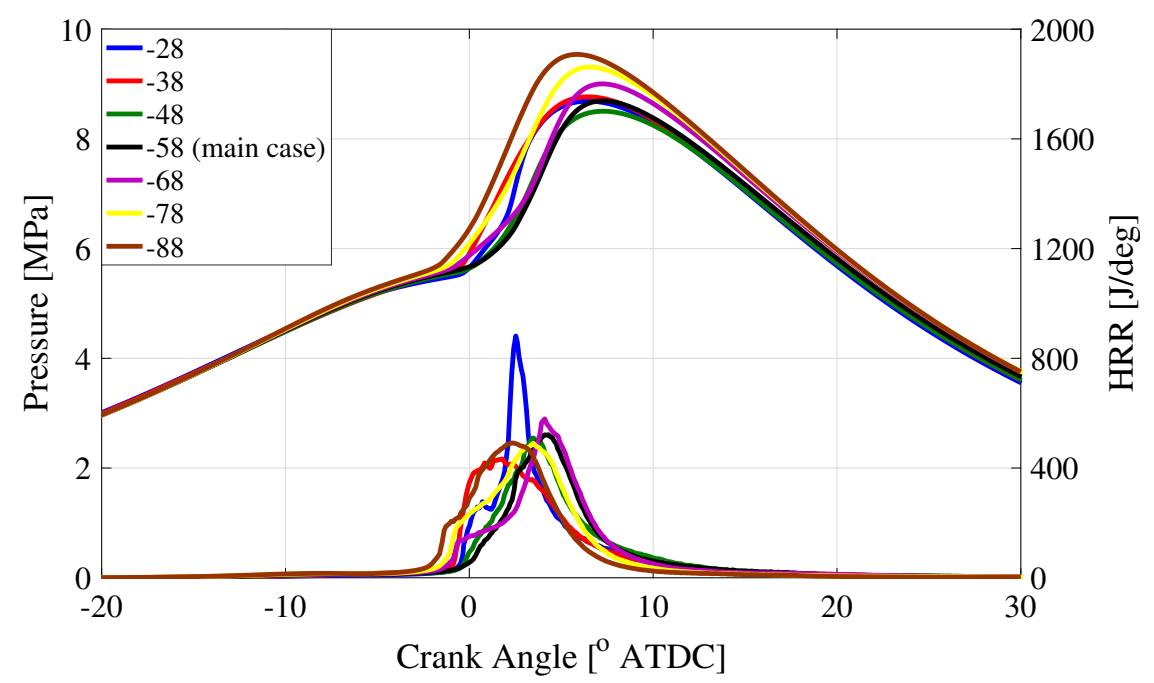

Figure 3: In-cylinder pressure and HRR for the injection SOI timing sweep cases.

Figure 4 shows the evolution of in-cylinder equivalence ratio distribution for 


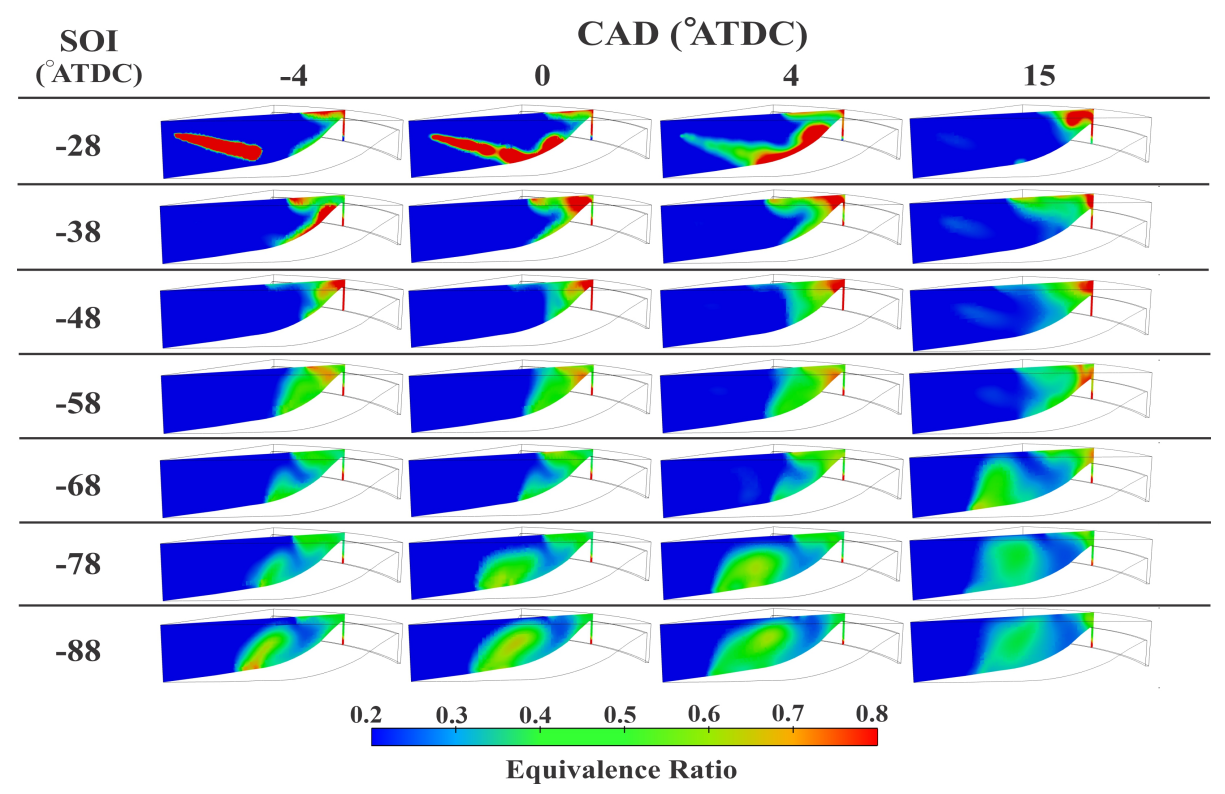

Figure 4: Evolution of local equivalence ratio distribution for the injection SOI timing sweep cases at $-4,0$, and $15^{\circ} \mathrm{ATDC}$.

each case. As seen from the results, at $-4^{\circ}$ ATDC, by sweeping the SOI timings to near-TDC, the local equivalence ratio distribution is shifted from the bowl to the liner wall as a result of the spray impingement with different regions at a fixed spray cone angle of $72.5^{\circ}$. In addition, mixing time is decreased that leads to stratify the local equivalence ratio and the reactivity. At SOI of $-28^{\circ}$ ATDC, because of lower reactivity of iso-butanol doped with DTBP than diesel fuel [19], as a high reactive fuel, the equivalence ratio contour indicates an increase in the level of incomplete combustion to explain the presence of richer regions even after the combustion event, as seen at $15^{\circ}$ ATDC. Hence, it is expected to have a high amount of UHC, as shown in Figure 5 . Thus, it is interesting to note that the retarding of a direct-injected fuel, especially which has a less reactivity similar to isobutanol+20\% DTBP used in this study, would result in poor mixing of the fuel and incomplete combustion. Advancing SOI timing to $-88^{\circ}$ ATDC, divides the distribution of local equivalence ratio into two separate regions within the combustion chamber, increases the portion of region that is close to bowl, and also 
produces a leaner mixture that results in a reduction in $\mathrm{CO}$ and $\mathrm{NO}_{x}$ emissions, as will be shown in the following.

Figure 5 shows performance and emissions variations for each sweep based on comparison to the limits of the Environmental Protection Agency's (EPA) 2010 for the emissions related to the heavy duty engine (i.e., $0.26,0.013,20.9$, and 0.2 $\mathrm{g} / \mathrm{kW}-\mathrm{hr}$ for $\mathrm{NO}_{x}$, soot, $\mathrm{CO}$, and UHC, respectively). As indicated, the SOI of $88^{\circ}$ ATDC produces the highest GIE and combustion efficiency, with a maximum efficiency of 51.3 and 0.96 , respectively, and the relatively lower emissions compared with the other cases. It can be shown that if both spray impingements on the liner wall occur at the early SOI timings (i.e., from SOI of $-88^{\circ}$ to $-68^{\circ} \mathrm{ATDC}$ ), the discrepancies in the performance and emissions are minimal, having a $1 / 10$ ${ }^{\circ}$ (combustion-duration) $)^{\circ}$ SOI. However, retarding the SOI from $-68^{\circ}$ to $-48^{\circ}$ ATDC leads to a substantial drop in the GIE at approximately constant combustion duration. The SOI of $-48^{\circ} \mathrm{ATDC}$ shows the highest amount of $\mathrm{CO}$ emissions because there is an inability to oxidize CO due to accumulation of DI fuel in the cooler regions, as previously shown in Figure 4. In addition to this, the cooling effect of isobutanol is increased by retarding of SOI timing, therefore, it could have an adverse impact on CO. All cases exhibit the RI under the limit (i.e., $\left.<5 \mathrm{Mw} / \mathrm{m}^{2}\right)$ [4], except in the SOI of $-28^{\circ}$ ATDC due to the sudden combustion. Here, the ringing intensity (RI) is the measure of the noise of combustion and is calculated by the Eng's correlation [48], as follows:

$$
R I\left(M W / m^{2}\right)=\frac{1}{2 \gamma} \frac{\left(0.05(d P / d t)_{\max }\right)^{2}}{P_{\max }} \sqrt{\gamma R T_{\max }}
$$

Where $\gamma$ is the ratio of heat capacity of the gas, $(\mathrm{dP} / \mathrm{dt})_{\max }$ is the maximum pressure rise rate, $\mathrm{P}_{\max }$ is the maximum of in-cylinder pressure, $\mathrm{R}$ is the ideal gas constant, and $\mathrm{T}_{\max }$ is the maximum in-cylinder gas temperature that is calculated during the simulation.

Also, by retarding SOI from $-88^{\circ}$ to $-58^{\circ}$ ATDC, the $\mathrm{NO}_{x}$ emissions increase slightly, but further retarding leads to a sharp increase in $\mathrm{NO}_{x}$ emissions due to the presence of rich regions and impingement of the direct injected fuel to the hot bowl surface. These results have a deviation from earlier studies such as Nazemi 


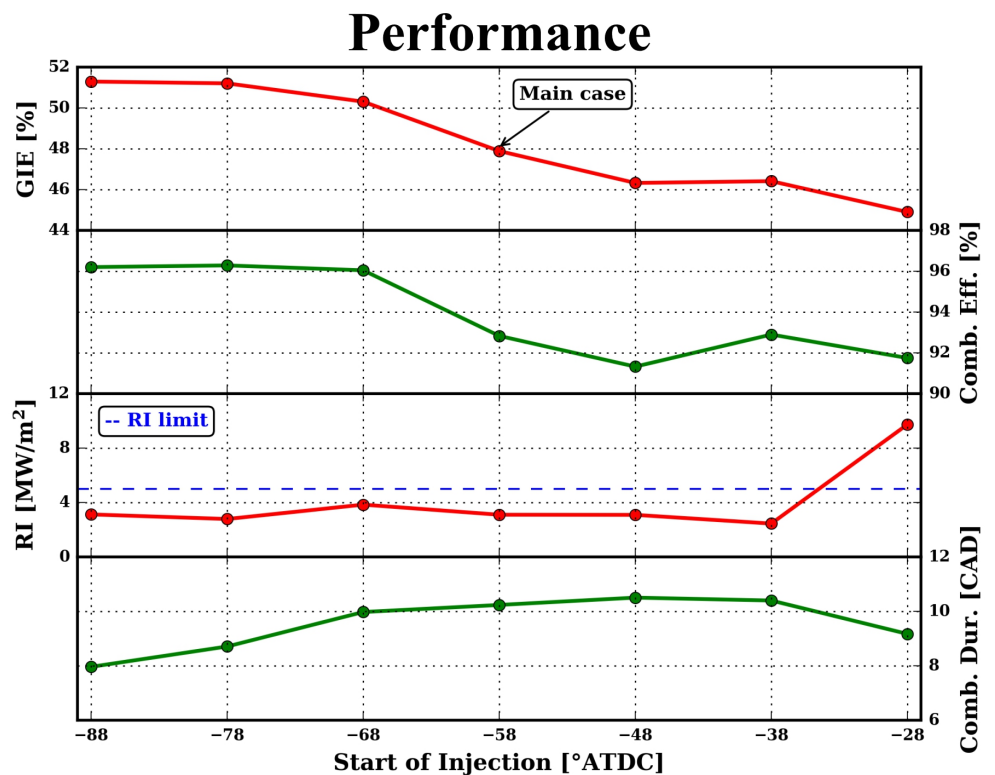

Emissions

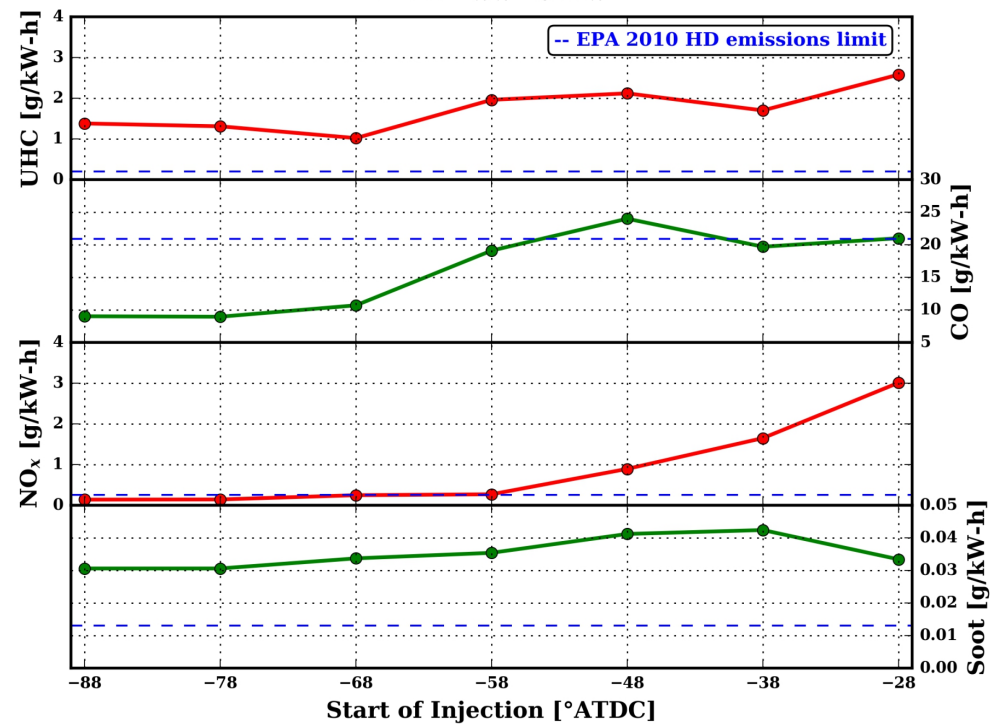

Figure 5: Performance and emissions variations as a function SOI timing sweep. 
and Shahbakhti [49], which showed that advancing start of injection timings from the conventional dual-fuel RCCI baseline (i.e., $-58^{\circ}$ ATDC) could decrease $\mathrm{NO}_{x}$. However, it occurred at the expense of $\mathrm{CO}, \mathrm{HC}$ and also soot emissions. The discrepancies are due to differences in base fuels and piston bowl profile.

At this point, it would be suggested to have better performance and lower emissions at early injection timings when the amount of DI fuel is relatively high.

\subsection{Effect of spray cone angle}

The effects of spray cone angle were explored by changing the angle from $45^{\circ}$ to $80^{\circ}$ with a $5^{\circ}$ degree step. Spray cone angle is defined as the angle between the cylinder axis and the cone axis of injected parcels that is the half of included angle. Figure 6 demonstrates the in-cylinder pressure and the corresponding heat release rate for the abovementioned changes; as seen, the onset of combustion is obviously retarded, and the peak of pressure and HRR is suppressed by increasing the cone angle from $45^{\circ}$ up to $65^{\circ}$. However, the pressure and HHR are confined to a similar range for angle of $70^{\circ}$ to $80^{\circ}$, and there is also no discernible change for the peak of those cases, as shown. In all cases, the narrowest angle has the maximum peak of pressure and heat release rate because of better mixing of high reactive fuel with air, which results in better consuming of the fuel that leads to a reduction of UHC, as will be shown in the following.

Injection timings of a traditional dual-fuel RCCI, which was adapted from Koci et al. [50] finding for highly dilute LTC, is based on spray targeting of both squish and bowl regions to reduce engine-out $\mathrm{CO}$ and $\mathrm{HC}$ emissions. While the current bathtub piston bowl compared with stock piston have a negligible squish region [51], there is a need for a better understanding of the distribution of DI fuel parcels in both injections by altering spray cone angle. Figure 7 shows the interaction between the spray plume and the combustion chamber walls in both injection events for each case. At the first injection event, at $-58^{\circ}$ ATDC, spray plumes corresponding to the narrowest angle until angle of $55^{\circ}$ reside within the

piston bowl. Spray cone angle of $60^{\circ}$ injects parcels into the crevice regions di- 


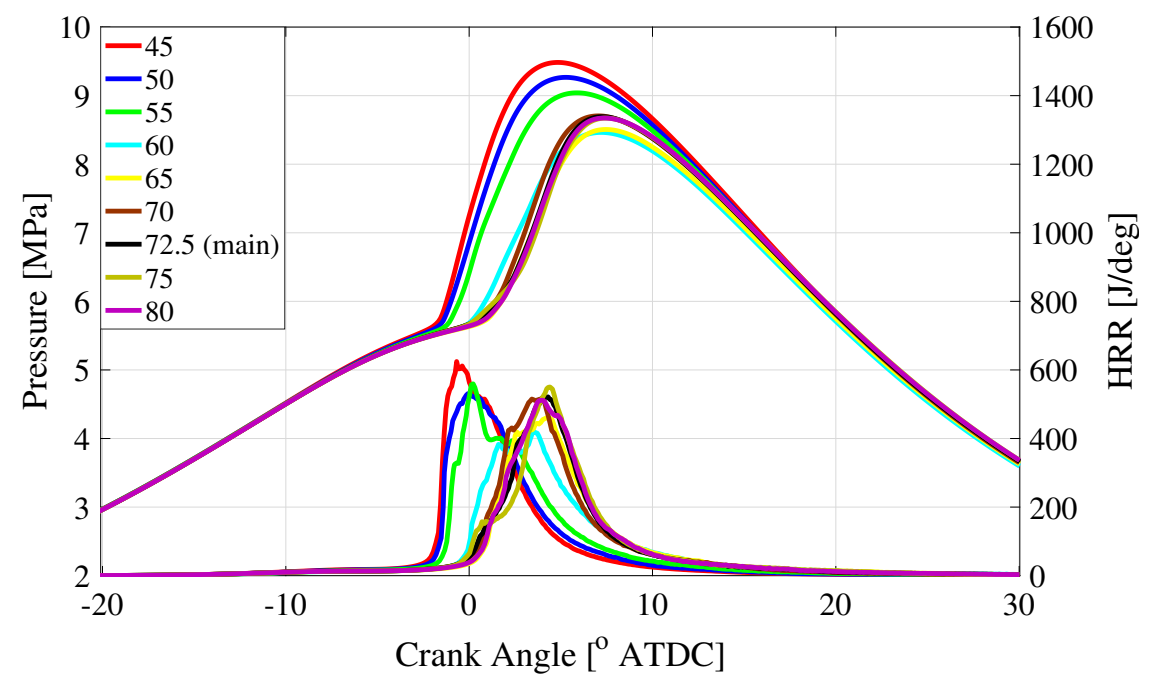

Figure 6: In-cylinder pressure and HRR for the variation of spray cone angle.

rectly; also, wider angles than $60^{\circ}$ penetrate parcels into the cylinder wall. At the second injection event, at $37^{\circ}$ ATDC, each spray plume subsequently impinges on the piston wall by increasing the angle up to the baseline, respectively. However, either angles of $75^{\circ}$ or $80^{\circ}$ still target outside of the piston bowl surface. As a general result, determining the spray targeting can have a key role in combustion and its corresponding emissions. This role could be seen in Figure 9 .

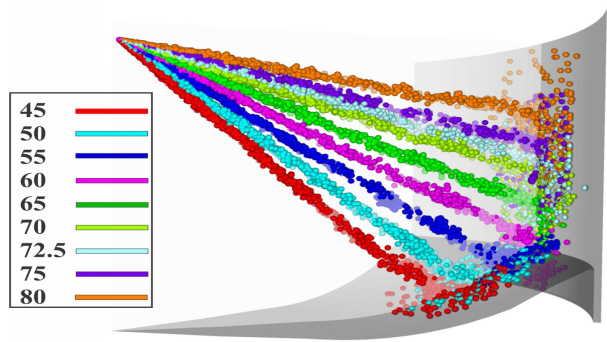

$\underline{-52}$ ATDC

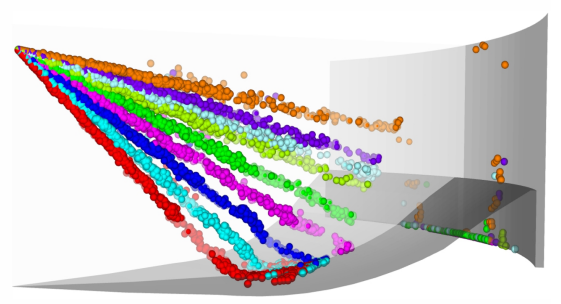

$\underline{-33 \text { ATDC }}$

Figure 7: Interaction of the spray targeting and the walls for both of fuel injection event in isobutanol + isobutanol+20\% DTBP RCCI case.

In order to realize visually how the distribution of parcels affects the mixing 


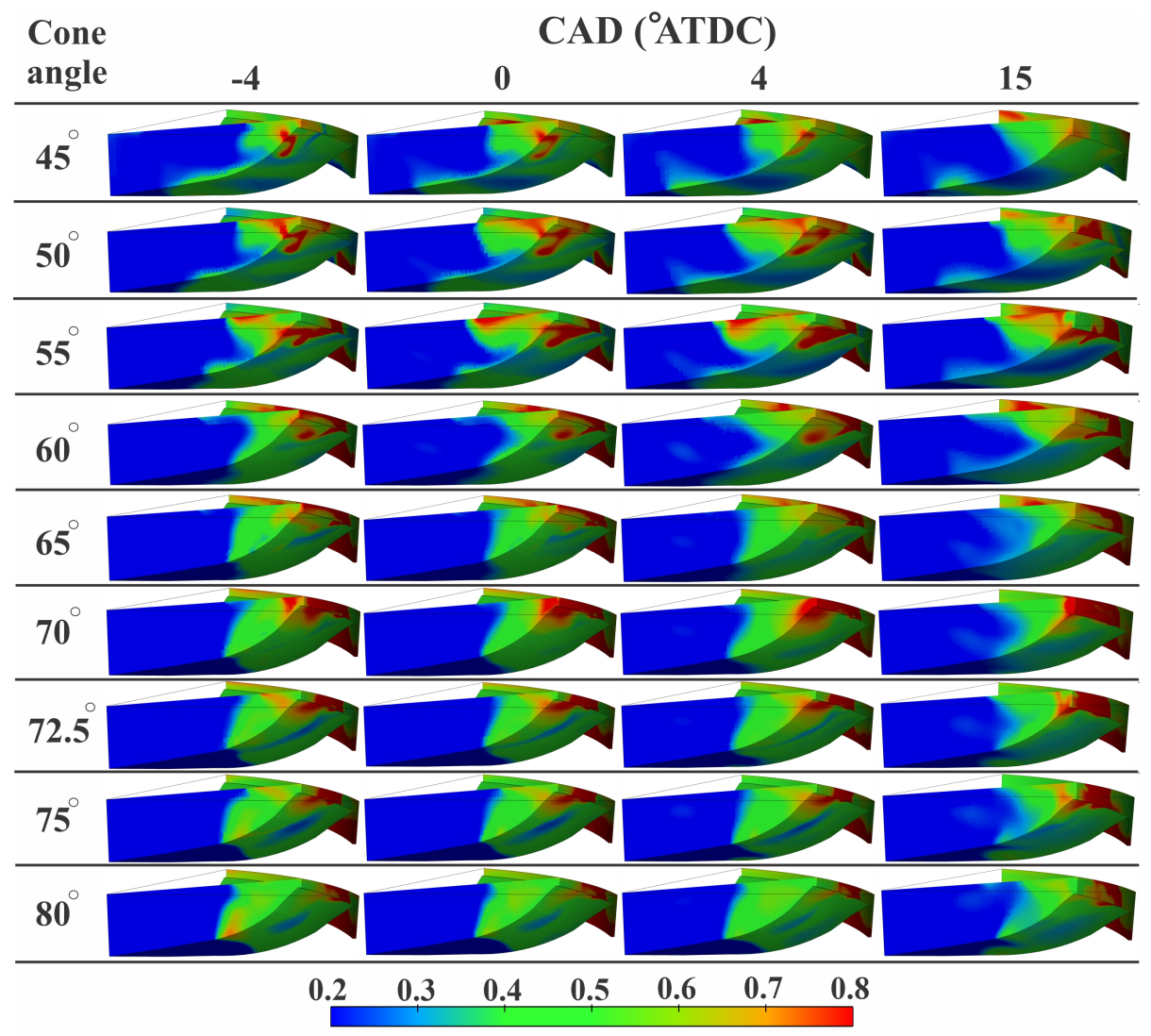

Equivalence Ratio

Figure 8: Evolution of local equivalence ratio distribution for the varied spray cone angle cases at $-4^{\circ}$, $0^{\circ}$, and $15^{\circ}$ ATDC.

process, Figure 8 shows the evolution of equivalence ratio distribution on a cut plane coincident with the spray axis, the piston, and the liner walls, at various crank angles for all cases. As seen, the narrowest angle case tends to develop the equivalence ratio from the liner wall towards near to the center of piston bowl, and this tendency is decreased by increasing the angle. It could be noted that having more high reactivity fuel within the piston bowl surface creates a mixture rich enough to attain complete combustion due to higher piston surface temperature [49, 52, as seen from HRR results. In accordance with Figures 7 and 8 , the cases associated with spray angle of $60^{\circ}$ and $65^{\circ}$ have the higher amounts of high 
reactivity fuel within the crevice regions, which have the lowest temperature, results in more mixing time (i.e., ignition delay). However, this added mixing time causes a negative effect on combustion, leading to lower peak in-cylinder pressure. A significant portion of high reactive fuel parcels impinge on the cylinder wall and the rest of those accumulate within the crevice regions by increasing angle from $65^{\circ}$. Consequently, an improvement is observed in combustion due to the reflection of parcels into the center of cylinder that makes a more uniform mixture.

Accordingly, Figure 9 shows the performance and emissions characteristics as a function of spray angle. From the performance standpoint, a similar trend occurs for GIE, RI, and combustion efficiency, while the duration of combustion is almost the exact opposite of that. As a results, the highest efficiencies happen wherever the spray angle avoids the range of $60^{\circ}$ to $70^{\circ}$. However, the lowest values of RI lie within this range that could induce a RI-GIE trade-off. In addition, Figure 9 shows that the mentioned range could produce high unburned hydrocarbon, $\mathrm{CO}$, and soot emissions. It can also be seen that $\mathrm{NO}_{x}$ emissions drop because increasing spray angle prevents direct-injected fuel from high temperature regions (i.e., piston surface).

In summary, for the baseline injection timings, angles from $45^{\circ}$ to $55^{\circ}$ keep both injected high reactive fuel within the piston bowl region, but total high reactivity fuel quantity separates into different regions by increasing the angle from $55^{\circ}$. These results are not in close accordance with Nazemi et al. [49] due to different piston bowl geometry used in this study.

\subsection{Effect of injection pressure}

To gain further insight into the achievement of the optimal injection strategy, the effects of important injection parameters is related to injector characteristics are considered. In this section, the effects of injection pressure are explored by increasing from the baseline to $\mathrm{p}=1600$ bar. For the same amount of delivered direct-injected fuel, duration of injection is decreased by increasing injection pressure, in each case. Figure 10 shows the results of in-cylinder pressure 

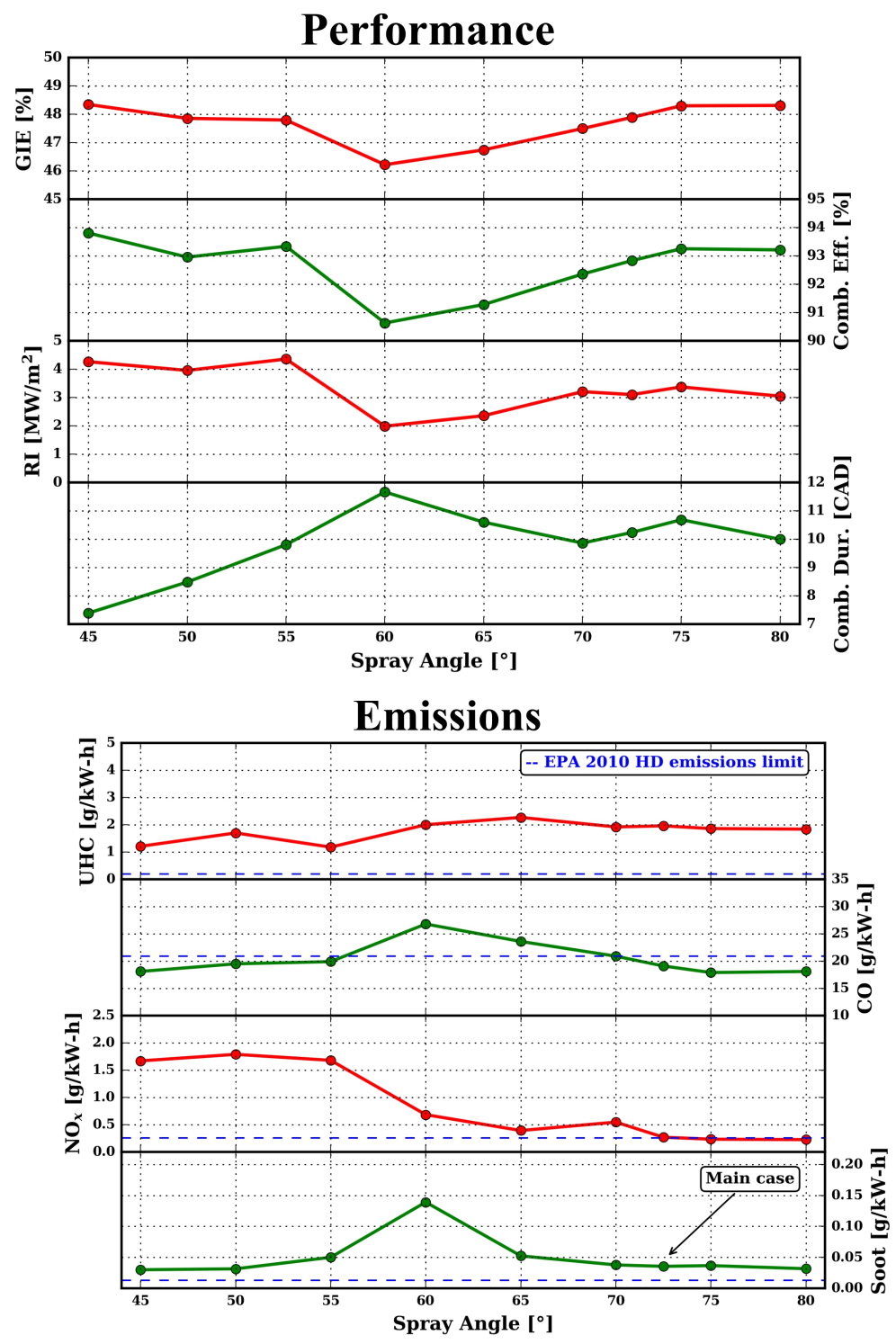

Figure 9: Performance and emissions variations as a function of varied spray cone angle. 
and HRR for the mentioned variations of injection pressure. As seen, the trends for pressures and HRR are somewhat similar in all cases, but there is a visible change in the case of 1600 bar, so need to consider in following.

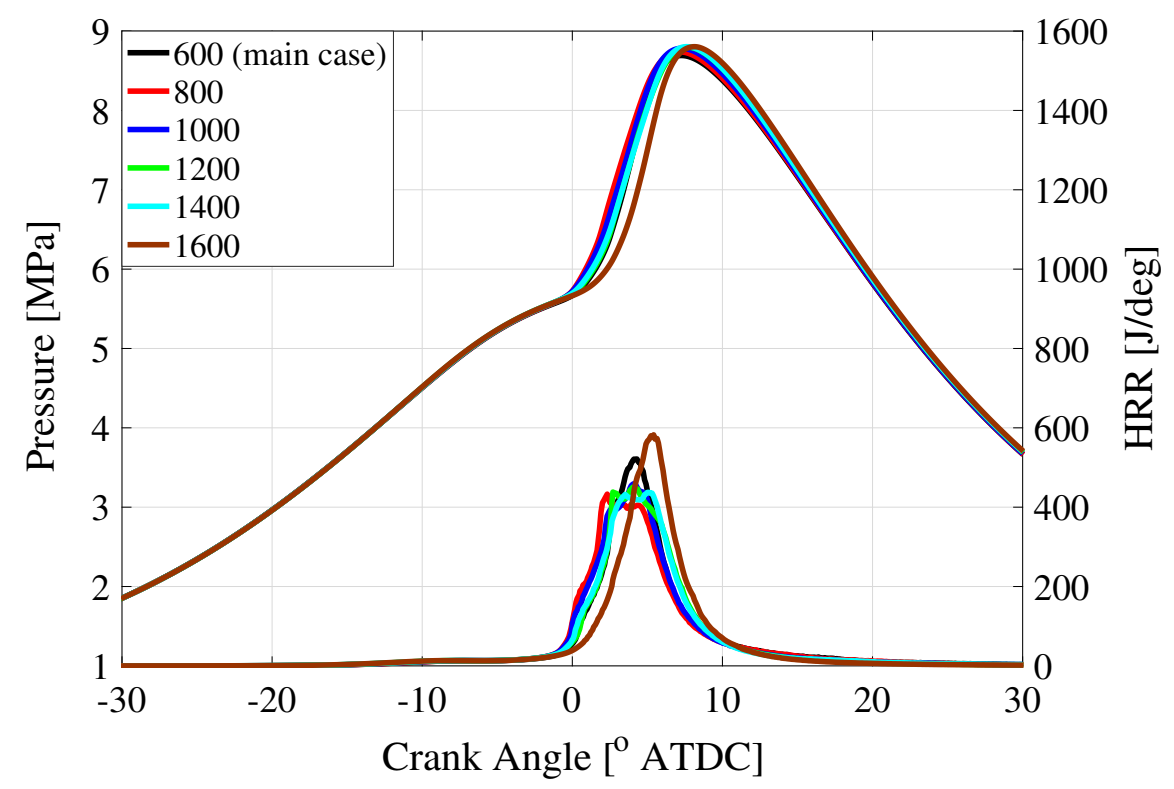

Figure 10: In-cylinder pressure and HRR for the variation of injection pressure.

Figure 11 shows the performance and emissions variations versus injection pressure. It is seen that the GIE can achieve its peak value of over $49 \%$ with the injection pressure of 1600 bar. Combustion efficiency is enhanced steadily until the injection pressure of 1400 bar due to improved oxidization of CO and UHC, as shown. However, the result shows a reduction in combustion efficiency at the injection pressure of 1400 compared to 1600 bar, because UHC is increased suddenly by a factor of 2 , even with a $15 \%$ reduction in CO. In order to justify this behavior, Figure 12 demonstrates the temperature and local equivalence distributions. As can be seen from temperature distribution at $15^{\circ}$ ATDC, the premixed charge of isobutanol and air within the crevice volume is communicated with the surrounding cooler regions during the expansion stroke, so UHC can- 


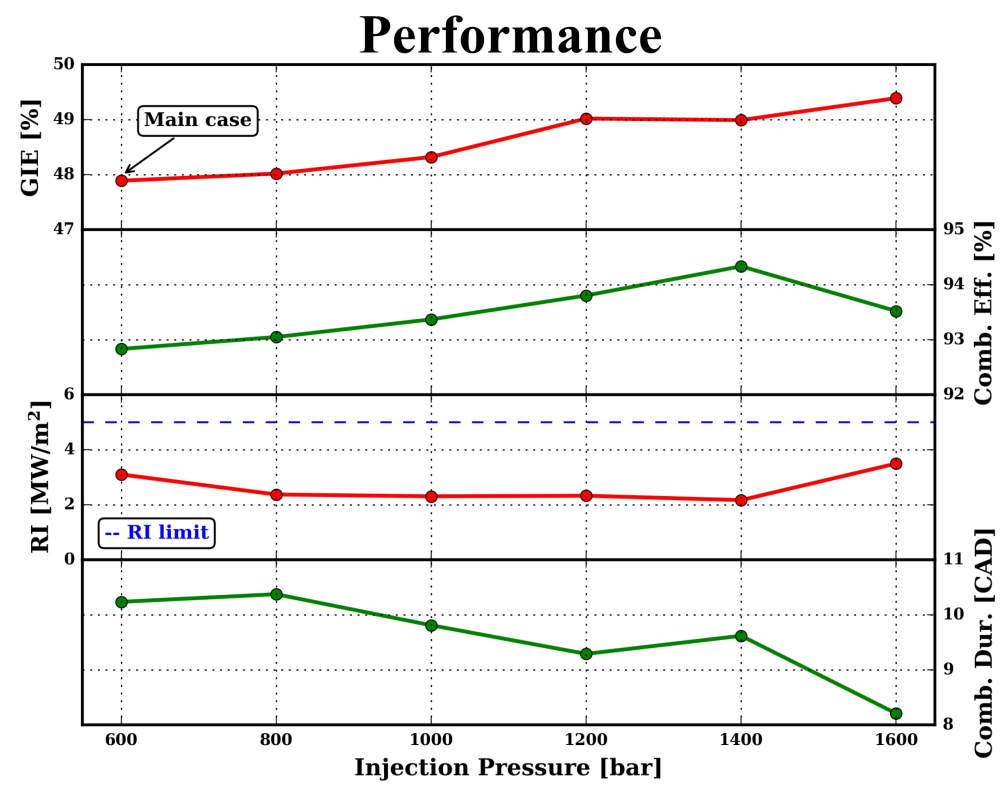

Emissions

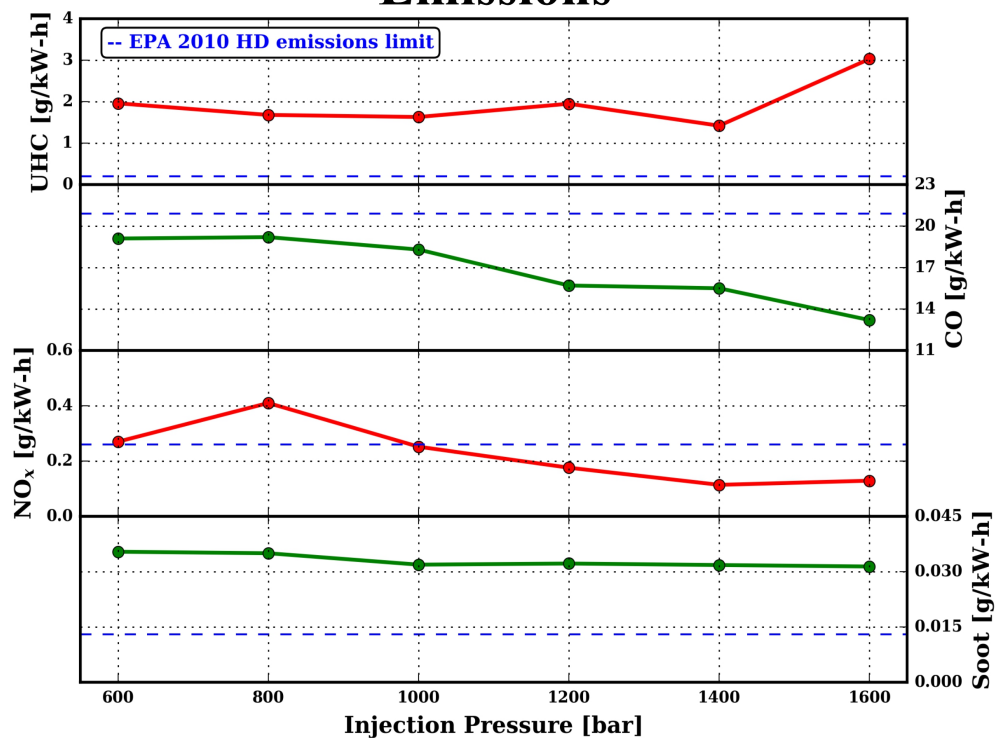

Figure 11: Performance and emission variations as a function of injection pressure. 
not oxidize, and results in an incomplete combustion in $\mathrm{p}=1600$ bar. It should be noted that UHC emissions tend to form near the crevice regions in the piston bowl geometry used in the current study.

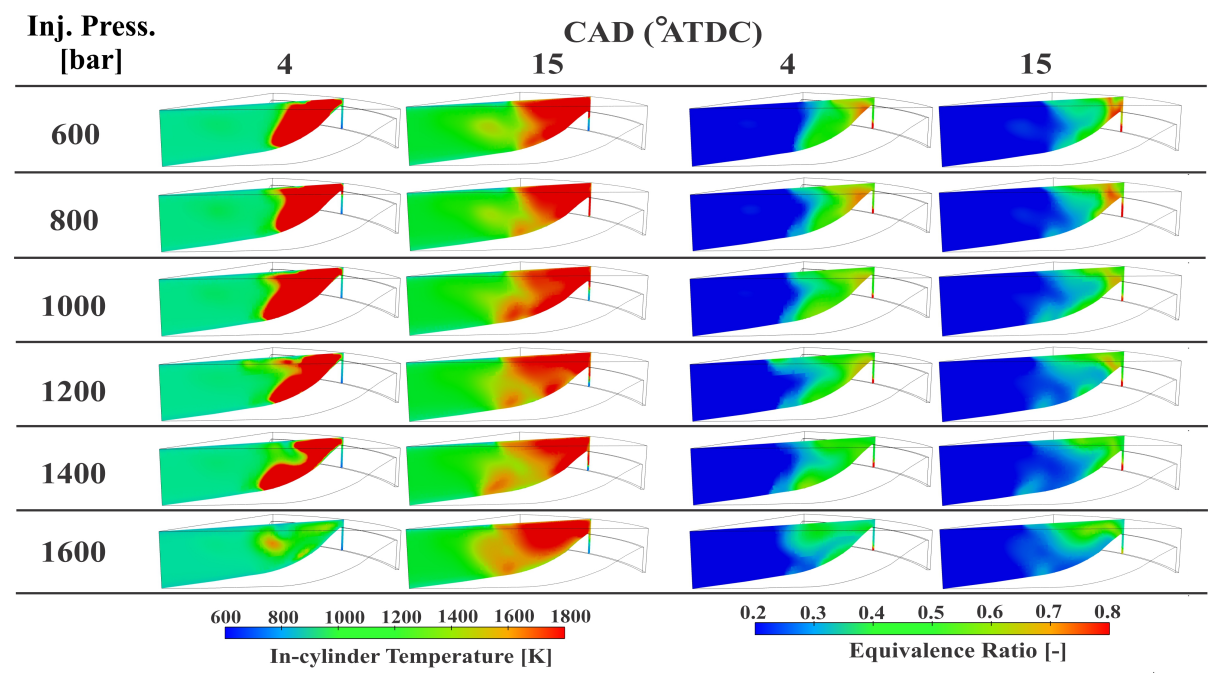

Figure 12: Evolution of temperature and local equivalence ratio distributions for the varied injection pressure cases at $4^{\circ}$, and $15^{\circ}$ ATDC.

Also, the trends for emissions show that the soot emissions remain fairly constant by increasing the injection pressure, while $\mathrm{NO}_{x}$ emissions are reduced by about $0.14 \mathrm{~g} / \mathrm{kW}$-hr from the baseline, due to the higher level of homogeneity. Increasing the injection pressure decreases the duration of injection timing, therefore results in higher mixing time (i.e., longer ignition delay) [53]. As seen at $4^{\circ}$ ATDC, the temperature contour shows a significant longer ignition delay at p=1600 bar among all cases. but, as seen from Figure 12 and HRR result, combustion duration is shortened that combustion is terminated sooner than the other cases, which yields an increased RI and peak value of HRR. Therefore, HCCI-like combustion could be achieved for increasing the injection pressure further than of 1400 bar.

These results suggest that, for the fixed baseline conditions and piston bowl geometry, increasing the injection pressure can improve GIE, combustion effi- 
ciency, and engine-out emissions, if the injection pressure does not exceed 1400 bar, which means that it should prevent the charge preparation from being an overly well-mixed charge similar to HCCI.

\subsection{Effect of DI ratio}

In this final section, the effects of DI ratio on the baseline case are discussed. The ratio between the amounts of isobutanol+20\% DTBP, as the direct-injected fuel, and the amounts of premixed isobutanol plus isobutanol+20\% DTBP, as the total fuel, is defined as DI ratio. As previously mentioned, DI ratio for the baseline case is near $60 \%$, and the decrease is conduced at $10 \%, 20 \%, 25 \%$, and $30 \%$. Based on the results of the previous sections, the best cases are SOI of $-88^{\circ}$ ATDC, injection pressure of $1400 \mathrm{bar}$, and spray angle of $45^{\circ}$.

Figure 13 shows the in-cylinder pressure and HRR in each case. As expected, the misfiring happens below a particular DI ratio due to the lack of the presence of a strong ignition source. As seen from Figures $13 \mathrm{a}$ and $13 \mathrm{~b}$, while the combustion duration lengthens, the premixed isobutanol does not achieve complete combustion when the DI ratio is below $40 \%$ in the baseline and 1400 bar injection pressure cases. As can be seen in Figure 13c, there is a similar combustion phasing to the baseline case in $-88^{\circ}$ ATDC SOI case for the DI ratio of $50 \%$ while improved peak pressure rise rate is visible. Similarly, the $45^{\circ}$ spray angle case for DI ratio of $40 \%$ is the one most resembling the baseline HRR, as seen in Figure $13 \mathrm{~d}$

The temperature and equivalence ratio distributions are shown in Figures 14 and 15 at $4^{\circ}$ and $-4^{\circ}$ ATDC, respectively. Note that, the combustion is retarded by decreasing the DI ratio, therefore, decreasing GIE is to be expected. In the baseline case, the accumulation of richer regions within the crevice regions is increased by decreasing DI fuel that leads to deterioration of combustion efficiency, as seen from equivalence ratio distribution. The $-88^{\circ}$ ATDC SOI case suggests that richer regions are away from the crevice regions, so the higher UHC is expected compared to the $45^{\circ}$ spray angle case.

To summarize the results, Figures 16 and 17 show the performance and emis- 


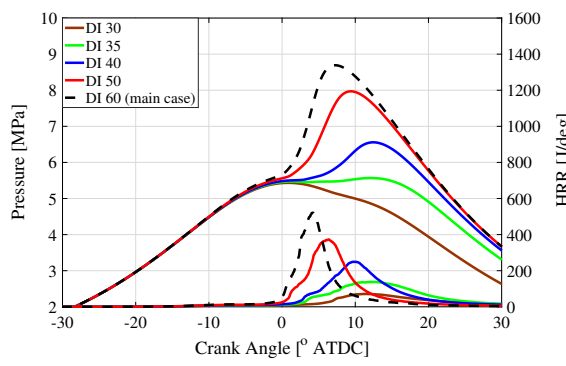

(a) The effects of decreasing DI ratio on baseline case

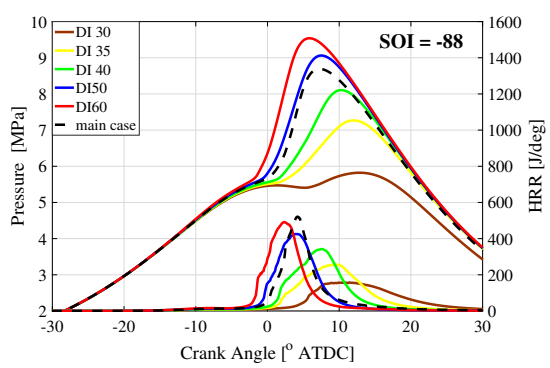

(c) The effects of decreasing DI ratio on $-88^{\circ}$ ATDC SOI case

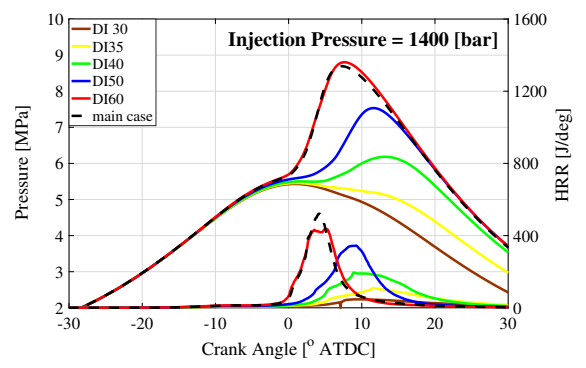

(b) The effects of decreased DI ratio on 1400 bar injection pressure case

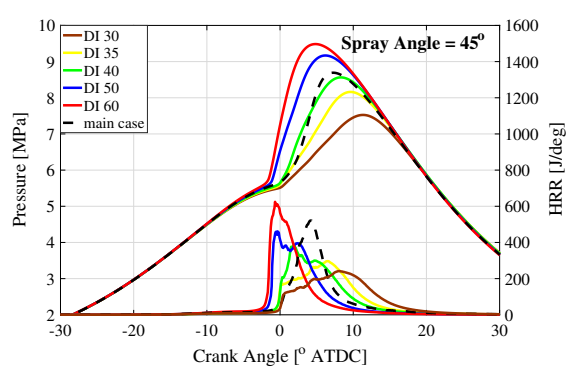

(d) The effects of decreasing DI ratio on $45^{\circ}$ spray angle case

Figure 13: Effects of decreasing of DI ratio on in-cylinder pressure and HRR corresponding to (a) the baseline case, (b) $-88^{\circ}$ ATDC SOI timing case, (c) 1400 bar injection pressure case, and (d) $45^{\circ}$ spray angle case 


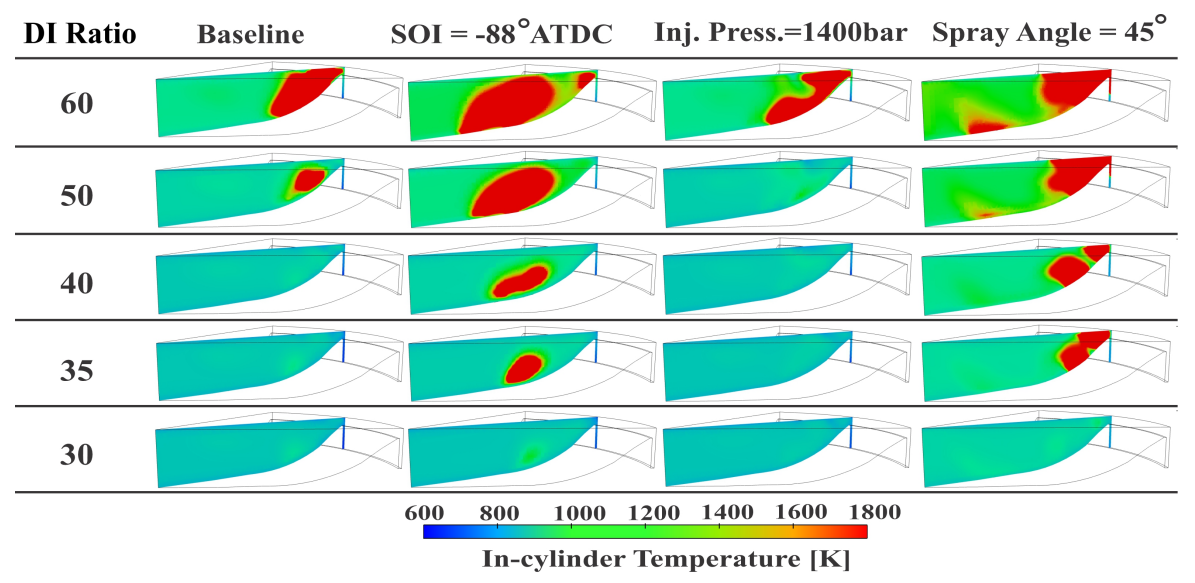

Figure 14: Temperature distribution for each case at $4^{\circ}$ ATDC.

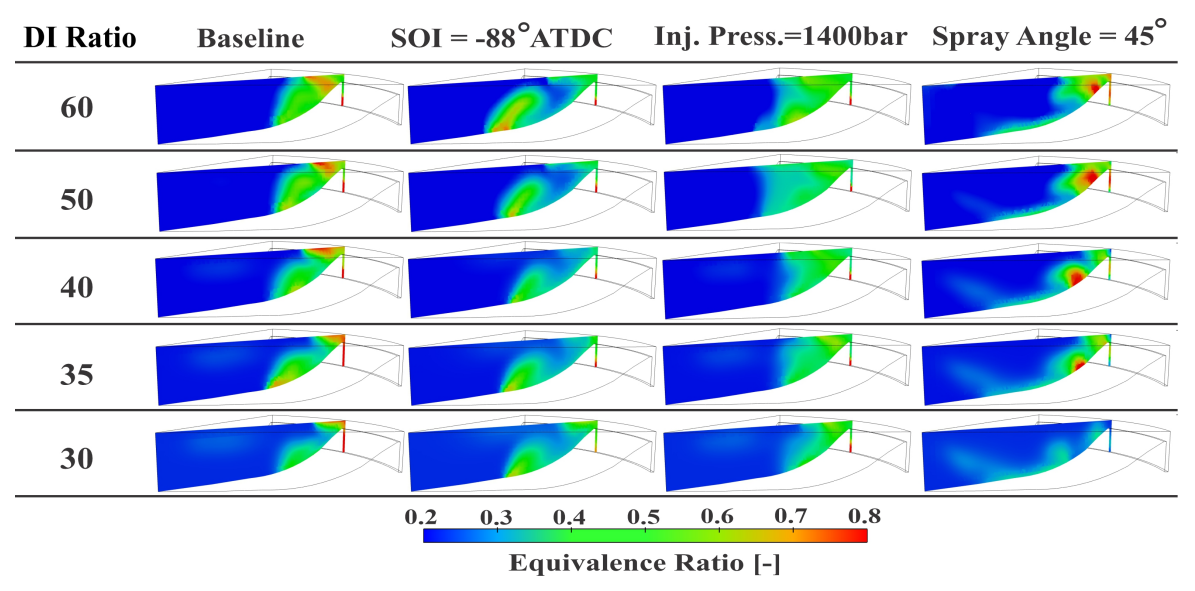

Figure 15: Local equivalence ratio distribution for each case at $-4{ }^{\circ}$ ATDC.

sions variations as a function of DI ratio, respectively. Decreasing the DI ratio decreased the GIE and combustion efficiency, but the $45^{\circ}$ spray angle case shows a negligible variation across the decreased range of DI ratio. Also, this trend can be seen in the $-88^{\circ}$ ATDC SOI case before the DI ratio of $35 \%$. Additionally, note that the noise of combustion (i.e., RI) is also decreased because decreasing the DI ratio causes an extended combustion duration. Also, it is obvious that a reduction trend of $\mathrm{NO}_{x}$ is observed in all cases, while this trend is too intense in the $45^{\circ}$ spray angle case to bring $\mathrm{NO}_{x}$ below the limit EPA 2010. As expected from 


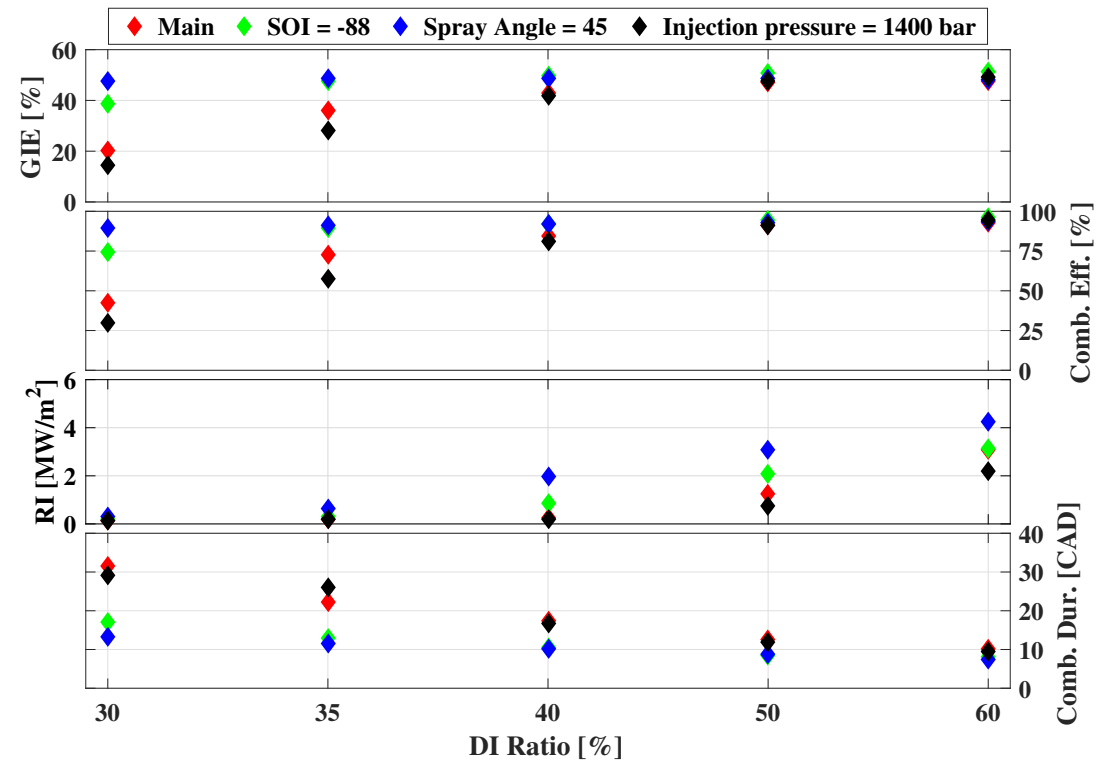

Figure 16: Performance variations as a function of DI ratio for each case.

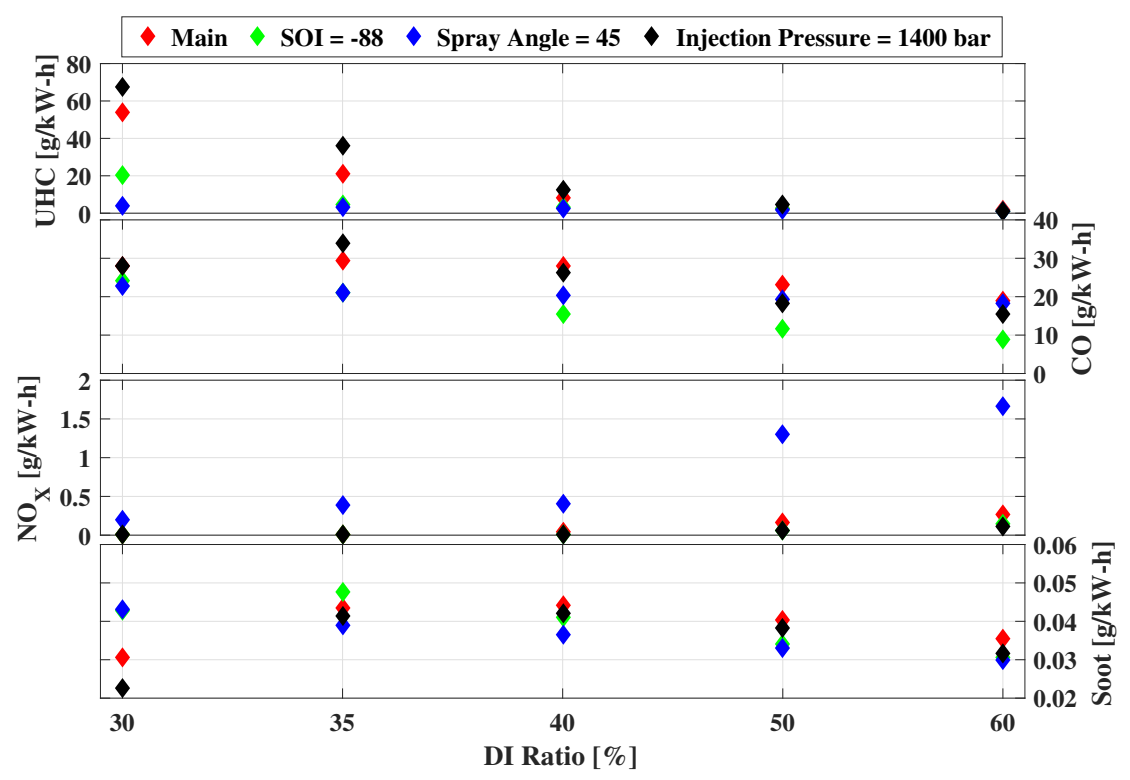

Figure 17: Emissions variations as a function of DI ratio for each case. 
the result of combustion efficiency, the increasing of $\mathrm{CO}$ and UHC increases the level of incomplete combustion while $\mathrm{CO}$ and UHC remains relatively constant in the spray angle case. That is, spray angle of $45^{\circ}$ could be provided the benefit of reducing $\mathrm{NO}_{x}$ emissions while maintaining high performance and other emissions by reduction of $\mathrm{DI}$ ratio. Nevertheless, $\mathrm{NO}_{x}$ is still high relative to the baseline case. Also, the $-88^{\circ}$ ATDC SOI case with DI ratio of $40 \%$ compared to the baseline case indicates an improved GIE of $3.5 \%$, reduced $\mathrm{CO}$ and $\mathrm{NO}_{x}$ by 3.56 and $0.254 \mathrm{~g} / \mathrm{kW}-\mathrm{hr}$, respectively, while combustion efficiency is held nearly constant. As a consequence, a $20 \%$ reduction of DI ratio is achievable by two cases corresponding to the SOI of $-88^{\circ}$ ATDC and spray angle of $45^{\circ}$.

\section{Conclusions}

In the present study, a single-fuel RCCI fueled with isobutanol and isobutanol+20\% DTBP was investigated numerically by using CONVERGE CFD tool. To summarize the major findings from this numerical investigation, the following conclusions can be drawn:

1. The SOI timing was swept in order to recognize the effects of each sweep on the performance and emissions characteristics. The chosen appropriate range for these sweeps is between $-68^{\circ}$ and $-88^{\circ}$ ATDC in which efficiency and emissions characteristics are better than the base and late SOI timings cases. Among all simulation cases, it was found that the maximum GIE and combustion efficiency values (i.e., 51.3\%, and 96.2\%) belong to SOI of $-88^{\circ}$ ATDC, which are about $7 \%$, and $3.7 \%$ higher than the base case(i.e., $\left.\mathrm{SOI}=-58^{\circ} \mathrm{ATDC}\right)$, respectively; Also, $\mathrm{NO}_{x}$ and $\mathrm{CO}$ decreased by about 0.13 and $10 \mathrm{~g} / \mathrm{kW}-\mathrm{hr}$, respectively. Overall, it can be drawn that the gross indicated efficiency, combustion efficiency, ringing intensity, and CO, and $\mathrm{NO}_{x}$ emissions have much more sensitivity to SOI timing variations.

2. It was shown that the increasing injection pressure gradually increased GIE due to decreased heat losses, but the much more mixing time which 
related to the injection pressure beyond 1400 bar led to the combustion similar to HCCI, and also form a substantial UHC, therefore, a reduction of combustion efficiency. It was also indicated a slight continuous reduction in $\mathrm{CO}$ emissions while soot emissions and RI were remained fairly unaffected by increasing the injection pressure.

3. The results for the variations of spray cone angle showed that the location of each spray targeting on any regions of cylinder chamber walls played a leading role in mixing, and, in consequence, combustion, for a certain SOI timing, and piston bowl geometry; By varying both of them, it is needed to consider the spray targeting again. For the current piston bowl geometry used in this study, it was shown that the range of spray cone angle between $60^{\circ}$ and $70^{\circ}$ causes the accumulation of significant portion of fuel parcels within the crevice regions, and led to incomplete combustion. It was also seen that the combustion duration is more sensitive to variation of spray cone angle.

4. It was shown that a reduction of $20 \%$ in DI ratio can be achieved with the $-88^{\circ}$ ATDC SOI and $45^{\circ}$ spray angle cases while improved GIE is also obtained, compared to the baseline case; however, the corresponding $\mathrm{CO}$ and $\mathrm{NO}_{x}$ are improved only with the $-88^{\circ}$ ATDC SOI case. Therefore, the less gradient of isobutanol and isobutanol with cetane improver that resulted in high DI requirement could be reduced with altering the injection strategy such that the implementation of the single-fuel RCCI fueled isobutanol and isobutanol+20\% DTBP is more practical.

The authors believe that the results provide an excellent insight into singlefuel RCCI combustion which can be further used to optimize the injection strategy.

\section{Acknowledgement}

The authors would like to thank Prof. Reitz from University of WisconsinMadison for providing the data for simulation. The authors also thank Conver- 
gent Science Inc. for providing a free version of their CONVERGE package for academic purposes. 


\section{References}

[1] R. D. Reitz, Directions in internal combustion engine research, Combustion and Flame 1 (160) (2013) 1-8. doi:https://doi.org/10.1016/j. combustflame.2012.11.002

[2] S. Saxena, I. D. Bedoya, Fundamental phenomena affecting low temperature combustion and HCCI engines, high load limits and strategies for extending these limits, Progress in Energy and Combustion Science 39 (5) (2013) 457-488. doi:https://doi.org/10.1016/j.pecs.2013.05.002

[3] A. K. Agarwal, A. P. Singh, R. K. Maurya, Evolution, challenges and path forward for low temperature combustion engines, Progress in Energy and Combustion Science 61 (2017) 1-56. doi:https://doi.org/10.1016/j. pecs.2017.02.001.

[4] A. B. Dempsey, N. R. Walker, E. Gingrich, R. D. Reitz, Comparison of low temperature combustion strategies for advanced compression ignition engines with a focus on controllability, Combustion Science and Technology 186 (2) (2014) 210-241. doi:https://doi.org/10.1080/00102202.2013. 858137 .

[5] S. L. Kokjohn, R. M. Hanson, D. Splitter, R. Reitz, Fuel reactivity controlled compression ignition (RCCI): a pathway to controlled high-efficiency clean combustion, International Journal of Engine Research 12 (3) (2011) 209226. doi:https://doi.org/10.1177/1468087411401548.

[6] S. Kokjohn, R. Hanson, D. Splitter, J. Kaddatz, R. Reitz, Fuel reactivity controlled compression ignition (RCCI) combustion in light-and heavy-duty engines, SAE International Journal of Engines 4 (1) (2011) 360-374. doi: https://doi.org/10.4271/2011-01-0357.

[7] D. Splitter, R. Hanson, S. Kokjohn, R. D. Reitz, Reactivity controlled compression ignition (RCCI) heavy-duty engine operation at mid-and high-loads 
with conventional and alternative fuels, Tech. rep. (2011). doi:https: //doi.org/10.4271/2011-01-0363.

[8] A. Paykani, A.-H. Kakaee, P. Rahnama, R. D. Reitz, Progress and recent trends in reactivity-controlled compression ignition engines, International Journal of Engine Research 17 (5) (2016) 481-524. doi : https://doi .org/ $10.1177 / 1468087415593013$

[9] D. E. Nieman, A. B. Dempsey, R. D. Reitz, Heavy-duty RCCI operation using natural gas and diesel, SAE International Journal of Engines 5 (2) (2012) 270-285. doi:https://doi.org/10.4271/2012-01-0379.

[10] A.-H. Kakaee, P. Rahnama, A. Paykani, Influence of fuel composition on combustion and emissions characteristics of natural gas/diesel RCCI engine, Journal of Natural Gas Science and Engineering 25 (2015) 58 - 65. doi: https://doi.org/10.1016/j.jngse.2015.04.020

[11] A. Paykani, A.-H. Kakaee, P. Rahnama, R. D. Reitz, Effects of diesel injection strategy on natural gas/diesel reactivity controlled compression ignition combustion, Energy 90 (2015) 814-826. doi:https://doi.org/10.1016/ j.energy.2015.07.112.

[12] P. Rahnama, A. Paykani, R. D. Reitz, A numerical study of the effects of using hydrogen, reformer gas and nitrogen on combustion, emissions and load limits of a heavy duty natural gas/diesel RCCI engine, Applied energy 193 (2017) 182-198. doi:https://doi.org/10.1016/j.apenergy. 2017. 02.023

[13] A. B. Dempsey, N. R. Walker, R. D. Reitz, Effect of cetane improvers on gasoline, ethanol, and methanol reactivity and the implications for RCCI combustion, SAE Int. J. Fuels Lubr. 6 (2013) 170-187. doi:https://doi. org/10.4271/2013-01-1678

[14] A. B. Dempsey, B. Das Adhikary, S. Viswanathan, R. D. Reitz, Reactivity Controlled Compression Ignition Using Premixed Hydrated Ethanol and Di- 
rect Injection Diesel, Journal of Engineering for Gas Turbines and Power 134 (8), 082806 (06 2012). doi:https://doi.org/10.1115/1.4006703.

[15] H. Liu, G. Ma, B. Hu, Z. Zheng, M. Yao, Effects of port injection of hydrous ethanol on combustion and emission characteristics in dual-fuel reactivity controlled compression ignition (RCCI) mode, Energy 145 (2018) 592 - 602. doi:https://doi.org/10.1016/j.energy.2017.12.089

[16] Y. Li, M. Jia, Y. Liu, M. Xie, Numerical study on the combustion and emission characteristics of a methanol/diesel reactivity controlled compression ignition (RCCI) engine, Applied Energy 106 (2013) 184 - 197. doi :https : //doi.org/10.1016/j.apenergy.2013.01.058.

[17] Y. Li, M. Jia, Y. Chang, M. Xie, R. D. Reitz, Towards a comprehensive understanding of the influence of fuel properties on the combustion characteristics of a RCCI (reactivity controlled compression ignition) engine, Energy 99 (2016) 69-82. doi:https://doi.org/10.1016/j.energy .2016.01.056

[18] H. Wang, D. DelVescovo, M. Yao, R. D. Reitz, Numerical study of RCCI and HCCI combustion processes using gasoline, diesel, iso-butanol and dtbp cetane improver, SAE Int. J. Engines 8 (2015) 831-845. doi:https: //doi.org/10.4271/2015-01-0850.

[19] D. DelVescovo, H. Wang, M. Wissink, R. D. Reitz, Isobutanol as both low reactivity and high reactivity fuels with addition of di-tert butyl peroxide (DTBP) in RCCI combustion, SAE Int. J. Fuels Lubr. 8 (2015) 329-343. doi: https://doi.org/10.4271/2015-01-0839.

[20] R. M. Hanson, R. D. Reitz, Effects of biofuel blends on transient reactivitycontrolled compression ignition engine combustion, International Journal of Engine Research 17 (8) (2016) 857-865. doi:https://doi.org/10.1177/ 1468087415622340 .

[21] J. Li, W. Yang, H. An, D. Zhao, Effects of fuel ratio and injection timing on gasoline/biodiesel fueled RCCI engine: A modeling study, Applied Energy 
155 (2015) 59 - 67. doi:https://doi.org/10.1016/j.apenergy. 2015. 05.114

[22] A. Gharehghani, R. Hosseini, M. Mirsalim, S. A. Jazayeri, T. Yusaf, An experimental study on reactivity controlled compression ignition engine fueled with biodiesel/natural gas, Energy 89 (2015) 558 - 567. doi:https: //doi.org/10.1016/j.energy.2015.06.014.

[23] F. D. Chuahy, S. L. Kokjohn, High efficiency dual-fuel combustion through thermochemical recovery and diesel reforming, Applied energy 195 (2017) 503-522. doi:https://doi.org/10.1016/j.apenergy.2017.03.078

[24] F. D. Chuahy, S. L. Kokjohn, Effects of reformed fuel composition in "single" fuel reactivity controlled compression ignition combustion, Applied Energy 208 (2017) 1 - 11. doi : https : //doi .org/10 .1016/j . apenergy . 2017 . 10 . 057 .

[25] D. Splitter, R. Reitz, R. Hanson, High efficiency, low emissions RCCI combustion by use of a fuel additive, SAE International Journal of Fuels and Lubricants 3 (2) (2010) 742-756. doi:https://doi.org/10.4271/ 2010-01-2167

[26] R. Hanson, S. Kokjohn, D. Splitter, R. D. Reitz, Fuel effects on reactivity controlled compression ignition (RCCI) combustion at low load, SAE Int. J. Engines 4 (2011) 394-411. doi:https://doi.org/10.4271/2011-01-0361.

[27] J. Kaddatz, M. Andrie, R. D. Reitz, S. Kokjohn, Light-duty reactivity controlled compression ignition combustion using a cetane improver, in: SAE Technical Paper, SAE International, 2012. doi:https://doi.org/10. 4271/2012-01-1110.

[28] Z. Xu, M. Jia, Y. Li, Y. Chang, G. Xu, L. Xu, X. Lu, Computational optimization of fuel supply, syngas composition, and intake conditions for a syngas/diesel RCCI engine, Fuel 234 (2018) 120 - 134. doi:https: //doi.org/10.1016/j.fuel.2018.07.003 
[29] A. B. Dempsey, S. Curran, R. D. Reitz, Characterization of reactivity controlled compression ignition (RCCI) using premixed gasoline and directinjected gasoline with a cetane improver on a multi-cylinder engine, SAE Int. J. Engines 8 (2015) 859-877. doi:https://doi.org/10.4271/ 2015-01-0855.

[30] E. Ansari, T. Menucci, M. Shahbakhti, J. Naber, Experimental investigation into effects of high reactive fuel on combustion and emission characteristics of the Diesel - Natural gas reactivity controlled compression ignition engine, Applied Energy 239 (2019) 948 - 956. doi :https://doi.org/10.1016/j. apenergy.2019.01.256.

[31] Z. Zheng, C. Li, H. Liu, Y. Zhang, X. Zhong, M. Yao, Experimental study on diesel conventional and low temperature combustion by fueling four isomers of butanol, Fuel 141 (2015) 109-119. doi:https://doi.org/10.1016/j. fuel.2014.10.053

[32] K. Richards, P. Senecal, E. Pomraning, et al., CONVERGE (v2. 2.0), Theory Manual, Convergent Science, Madison, WI (2014).

[33] M. A. Patterson, R. D. Reitz, Modeling the effects of fuel spray characteristics on diesel engine combustion and emission, SAE transactions (1998) 27-43doi:https://doi.org/10.4271/980131.

[34] R. REITZ, et al., Modeling atomization processes in high-pressure vaporizing sprays, Atomisation and Spray Technology 3 (4) (1987) 309-337.

[35] D. P. Schmidt, C. Rutland, A new droplet collision algorithm, Journal of Computational Physics 164 (1) (2000) 62-80. doi:https://doi.org/10. $1006 / \mathrm{jcph} .2000 .6568$

[36] P. J. O'Rourke, A. A. Amsden, The TAB method for numerical calculation of spray droplet breakup, Tech. rep. (1987). doi:https://doi.org/10.4271/ 872089 
[37] P. J. O'Rourke, A. Amsden, A spray/wall interaction submodel for the KIVA3 wall film model, SAE transactions (2000) 281-298doi : https: //doi .org/ 10.4271/2000-01-0271

[38] N. Frossling, Evaporation, heat transfer, and velocity distribution in twodimensional and rotationally symmetrical laminar boundary-layer flow, Tech. rep., National aeronautics and space admin langley research center hampton va (1956).

[39] Z. Han, R. D. Reitz, Turbulence modeling of internal combustion engines using RNG $\kappa-\varepsilon$ models, Combustion science and technology 106 (4-6) (1995) 267-295. doi:https://doi.org/10.1080/00102209508907782.

[40] Z. Han, R. D. Reitz, A temperature wall function formulation for variabledensity turbulent flows with application to engine convective heat transfer modeling, International journal of heat and mass transfer 40 (3) (1997) 613625. doi:https://doi.org/10.1016/0017-9310(96)00117-2.

[41] P. Senecal, E. Pomraning, K. Richards, T. Briggs, C. Choi, R. McDavid, M. Patterson, Multi-dimensional modeling of direct-injection diesel spray liquid length and flame lift-off length using CFD and parallel detailed chemistry, SAE transactions (2003) 1331-1351doi :https://doi .org/10.4271/ 2003-01-1043

[42] A. Babajimopoulos, D. Assanis, D. Flowers, S. Aceves, R. Hessel, A fully coupled computational fluid dynamics and multi-zone model with detailed chemical kinetics for the simulation of premixed charge compression ignition engines, International journal of engine research 6 (5) (2005) 497-512. doi:https://doi .org/10.1243/146808705X30503

[43] H. Wang, D. DelVescovo, Z. Zheng, M. Yao, R. D. Reitz, Reaction mechanisms and HCCI combustion processes of mixtures of n-heptane and the butanols, Frontiers in Mechanical Engineering 1 (2015) 3. doi:https://doi.org/ 10.3389/fmech.2015.00003. 
[44] H. Hiroyasu, T. Kadota, Models for combustion and formation of nitric oxide and soot in direct injection diesel engines, SAE transactions (1976) 513526doi:https://doi.org/10.4271/760129

[45] P. Senecal, E. Pomraning, K. Richards, S. Som, Grid-convergent spray models for internal combustion engine computational fluid dynamics simulations, Journal of Energy Resources Technology 136 (1) (2014) 012204. doi : https://doi.org/10.1115/1.4024861.

[46] B. Higgins, D. Siebers, C. Mueller, A. Aradi, Effects of an ignition-enhancing, diesel-fuel additive on diesel-spray evaporation, mixing, ignition, and combustion, in: Symposium (international) on combustion, Vol. 27, Elsevier, 1998, pp. 1873-1880. doi:https://doi.org/10.1016/S0082-0784(98) $80030-1$

[47] J. E. Dec, Y. Yang, Boosted HCCI for high power without engine knock and with ultra-low $\mathrm{NO}_{x}$ emissions-using conventional gasoline, SAE International Journal of Engines 3 (1) (2010) 750-767. doi:https://doi.org/10. 4271/2010-01-1086.

[48] J. Eng, Characterization of pressure waves in HCCI combustion (2002). doi:https://doi.org/10.4271/2002-01-2859.

[49] M. Nazemi, M. Shahbakhti, Modeling and analysis of fuel injection parameters for combustion and performance of an RCCI engine, Applied Energy 165 (2016) 135 - 150. doi:https ://doi . org/10.1016/j . apenergy . 2015. 11.093 .

[50] C. P. Koci, Y. Ra, R. Krieger, M. Andrie, D. E. Foster, R. M. Siewert, R. P. Durrett, I. Ekoto, P. C. Miles, Detailed unburned hydrocarbon investigations in a highly-dilute diesel low temperature combustion regime, SAE International Journal of Engines 2 (1) (2009) 858-879. doi:https: //doi.org/10.4271/2009-01-0928. 
[51] D. Splitter, M. Wissink, S. Kokjohn, R. D. Reitz, Effect of compression ratio and piston geometry on RCCI load limits and efficiency (2012). doi :https : //doi.org/10.4271/2012-01-0383.

[52] J. Lim, K. Min, The effects of spray angle and piston bowl shape on diesel engine soot emissions using 3-D CFD simulation (2005). doi : https://doi. org/10.4271/2005-01-2117.

[53] S. Kokjohn, R. Reitz, Investigation of charge preparation strategies for controlled premixed charge compression ignition combustion using a variable pressure injection system, International Journal of Engine Research 11 (4) (2010) 257-282. doi:https://doi.org/10.1243/14680874JER06409. 